\title{
New policies to deal with climate change and other drivers impacting on resilience to flooding in urban areas: the CORFU approach
}

\author{
Slobodan Djordjević ${ }^{1}$, David Butler ${ }^{1}$, Philippe Gourbesville ${ }^{2}$, Ole Mark ${ }^{3}$ and Erik Pasche ${ }^{4}$ \\ ${ }^{1}$ University of Exeter, North Park Road, Exeter EX4 4QF, United Kingdom, S.Djordjevic@exeter.ac.uk, \\ D.Butler@exeter.ac.uk \\ ${ }^{2}$ University of Nice-Sophia Antipolis, 930 route des Colles, 06903 Sophia Antipolis Cedex, France, \\ Philippe.Gourbesville@unice.fr \\ ${ }^{3} \mathrm{DHI}$, Agern Allé 5, DK-2970 Hørsholm, Denmark, Ole.Mark@dhigroup.com \\ ${ }^{4}$ Hamburg University of Technology, Denicke Strasse 22, D-21073 Hamburg, Germany (deceased)
}

\begin{abstract}
In the context of urban flood management, resilience is equal to resisting, recovering, reflecting and responding. The variety of causes of flooding and their consequences underpin the need for increased and internationally coordinated efforts to enhance technologies and policies for dealing with floods. This paper addresses this issue and presents some novel research ideas related to resilience to flooding in urban areas, which are under development within the EU FP7 project 'Collaborative research on flood resilience in urban areas' (CORFU). The approach adopted in this project aims to quantify the costeffectiveness of resilience measures and integrative and adaptable flood management plans for different scenarios of relevant drivers: urban development, socio-economic trends and climate changes. It is believed that the way in which the different models are being put together, combined with the variability of conditions in case study areas in Asia and in Europe, will ultimately enable more scientifically sound policies for the management of the consequences of urban flooding.
\end{abstract}

\section{Introduction}

Resilience is a concept that is frequently used in various fields, including ecology, economics and engineering. Inevitably, different definitions have been offered. In the context of flood management, resilience can be defined as the capacity of a system, community or society, potentially exposed to hazards, to adapt by resisting or changing, in order to reach and maintain an acceptable level of functioning and structure. This is determined by the degree to which the social system is capable of organising itself to increase this capacity for learning from past disasters for better future protection and to improve risk reduction measures. This can simply be restated as: resilience is equal to resisting, recovering, reflecting and responding. The benefit of the above definition is that change and learning from the past are required to achieve resilience. The focus on adaptability provides a framework to develop and assess flood management strategies (Gersonius, 2008).

At the time of writing of this paper, within a course of only two weeks, major flood events took place in Australia, Brazil, Colombia, the Philippines and Sri Lanka. The short-term impacts included hundreds of casualties, many displaced people and enormous damage to property and infrastructure. Subsequently, it will take years to get life back to normal in the affected areas, which will put huge pressure on national economies, cities, communities and individuals alike. Nevertheless, while these events were reported at the national level, they (with the exception of Australian floods) attracted relatively little attention in the global media, e.g. The Economist devoted only a small paragraph at the very end of its "The world this week" section, only after the news from daily politics (The Economist, 15 January 2011, page 6).

On the other hand, the European Floods Directive requires Member States to assess if water courses and coast lines are at risk from flooding, to map the flood extents, the assets and humans at risk in these areas, and to take adequate and coordinated measures to reduce flood risk. This is by no means an easy task and significant investments and other efforts are being made by governments, experts and various stakeholders to establish flood risk management plans focused on prevention, protection and preparedness.

The variety of causes of flooding and their consequences underpin the need for increased and internationally coordinated efforts to enhance technologies and policies for dealing with floods. This paper aims to address this issue and to present some novel research ideas related to resilience to flooding in urban areas. The paper is structured as follows. Climate change and other drivers impacting 
on flood risks are discussed in Section 2. Section 3 contains an overview of selected recently completed and ongoing research projects in which the Authors have been involved or on which their current research builds upon. Various elements of resilient flood management strategies are discussed in Section 4. Section 5 outlines the approach that is under development within the EU Framework Programme 7 funded project CORFU - Collaborative research on flood resilience in urban areas (www.corfu7.eu). This interdisciplinary project involves seventeen partners from Asia and Europe; it started in 2010 and will finish in March 2014.

\section{Drivers impacting on flood resilience}

An emerging challenge facing the world is global warming, and thus climate change. The evidence for global warming is compelling, with records showing that the global-average surface air temperature has risen by around $0.6^{\circ} \mathrm{C}$ since the beginning of the twentieth century, with about $0.4^{\circ} \mathrm{C}$ of this warming occurring since the 1970s. 1998 was the warmest year on record, and 11 of the 12 years from 1995 to 2006 rank among the 12 warmest years (IPCC, 2007).

The key outcome of global climate model scenario studies is that the global average annual precipitation will rise, although changes will vary from region to region. The annual average precipitation is expected to increase over most of northern Europe, the Arctic, Canada, the northeastern United States, tropical and eastern Africa, the northern Pacific, and Antarctica, plus northern Asia and the Tibetan Plateau in winter. It decreases in most of the Mediterranean region, northern Africa, northern Sahara, Central America, the American southwest, the southern Andes, and southwestern Australia during winter. Rainfall intensity will increase in tropical and high-latitude regions that experience overall increases in precipitation (IPCC, 2007).

Of particular relevance to flooding, the expectation is that precipitation will be more variable and with greater extremes. Taking the United Kingdom as an example of northern Europe, the climate will become warmer, so that by the 2080s the average annual temperature is expected to have risen by between $2^{\circ} \mathrm{C}$ and $3.5^{\circ} \mathrm{C}$. Temperature rises will lead to changes in precipitation patterns, although, little change is predicted in the annual amount of precipitation. Almost the whole of the UK is expected to be drier in the summer, with the greatest decreases in rainfall (up to 50\%) in the south-east. Summer soil moisture is also reduced by $40 \%$ or more over much of England. Heavy winter rainfall will become more frequent, with intensities that are currently experienced around once every 2 years becoming between $5 \%$ and $20 \%$ heavier by the 2080 s. Storm events in the summer will become more intense and more frequent. Sea level is predicted to rise everywhere, but more significantly in the south than the north (Hulme et al., 2002; Murphy et al., 2009).

The urban world is at a unique moment in time, especially in Asia. Three social, political, and financial movements are coming together in ways that will define future cities. The three movements are urbanization, decentralization and domestic capital market development (IBRD/WB, 2009). How a city is structured to manage its growth and vulnerabilities is critical. A city's access to domestic capital markets opens up opportunities to reduce its dependence on uncertain and/or politically motivated national government grants, subsidies, and allocations. Cities are implementing their identified priorities with capital improvement programs through a stream of dedicated resources.

Climate change will impact future city spatial patterns, growth, and development. The world's population is moving to cities; one-half of the global population is already urban. By 2030 at least 61 percent of the world's population will be living in cities (IBRD/WB, 2009). The figure for Europe is higher still: some $83 \%$ of the population - nearly 557 million - are expected to live in cities by 2050 (EC, 2010). Cities of the developing world will absorb 95 percent of all urban growth and will be home to almost 4 billion people, or 80 percent of the world's urban population (IBRD/WB, 2009). What was once dispersed rural poverty is now concentrated in urban informal and squatter settlements. More than one half of the world's slum population of 581 million is in Asia. By 2015, 12 of the largest 15 cities in the world will be in developing countries and 4 of those will be in Asia. The concentration of people in cities increases their opportunities as well as their vulnerabilities to natural hazards, civil strife, and climate change impacts.

The population's vulnerability increases not only from flooding due to more precipitation and storm surges, landslides, salt water intrusion and typhoons, but also from drought, earthquakes and other hazards. This is particularly the case where poor quality and ill-maintained infrastructure, low-quality building stock, and lower resilience of the high-density society come into play. For example, 8 out of the 
10 most populous cities in the world, including Tokyo/Yokohama, Seoul/Incheon, Osaka/Kobe/Kyoto, Metro Manila and Jakarta in East Asia, face moderate to high earthquake hazards. Similarly, 8 out of 10 of the most populous cities are located on the coast and are vulnerable to storm surges and tsunami waves. Resilient cities need to develop plans with climate change in mind and with new shelter options that are not located on marginal land in flood plains and steep slopes, at densities that control urban sprawl.

If current trends continue, a doubling of the developing world's urban population by 2030 will result in a tripling of their built-up areas. It is projected that Asia will see the largest increase during this time. While some of this increase is the natural consequence of urban population growth, inefficient land use and planning policies are partly to blame for urban sprawl. Furthermore, the lack of integrated land use and transport policies often do not allow for efficient, compact cities to develop with clusters of high density nodes that can support mass transit options and efficient grouping of residential developments, commercial services, and centres of employment. This would create lower transit emissions, less energy-intensive development, and greater proximity to shelters and services in the case of emergencies.

Decentralization, an ongoing force in Asia (IBRD/WB, 2009), represents a major shift in the way cities are managed. Local governments are now being endowed with responsibilities for self-management. Accessing domestic capital markets to address climate change impacts can make a difference to the way cities are governed.

European cities appear today as reflections of a global world; they have developed significant expertise and knowledge through history and various processes like immigration and integration. As with the Asian megacities, the challenge of climate adaptation now underlies the interest in developing the resilient dimension in the European urban environment.

\section{Overview of selected major research projects on flooding}

Several initiatives are taking place at the catchment scale, which is the recommended approach from the water-related directives of the European Union. A good example is given by the AMICE project Adaptation of the Meuse to the Impacts of Climate Evolutions - which is a transnational project under the InterReg IV B framework on the adaptation of this river and its catchment to the impact of flooding and low flows from climate change (www.amice-project.eu). Since 2009, the 17 partner organisations from Germany, Belgium, France and the Netherlands have been updating their knowledge about the river and how the local climate will change. They review published literature, test climate models, quantify the impacts of different factors and prepare good land-use maps. At the same time, a central issue for the project is linked to the governance and the strategies needed for the management of a complex catchment. There are many flood-water management constructions operating already in the Meuse river basin and more are planned. Herein lay some big challenges. How to design new water management structures that are able to deal comprehensively with flooding, drought and increasing water demand? How to adapt existing flood control measures to cope with ever more extreme events? Through AMICE, new approaches to these challenges are being tested by three highly innovative projects in Germany, Flanders and the Netherlands. The concepts used for new approaches are focused on a resilient approach where flooding is accepted and integrated into urban development plans.

In a very similar and parallel way, the FRC - Flood Resilien City (www.floodresiliencity.eu) - project also under the InterReg IV B framework has chosen to apply an integrated approach to sustainable flood risk management which has been developed and tested by the Scottish Government. This approach comprises four 'A's to be addressed in flood risk management plans and policies in the partner cities: Awareness, Avoidance, Alleviation and Assistance. The FRC strategy is to test and adapt the 4-A approach by applying it on the political, professional and public level (the 3 P's) in the partner cities. The FloodResilienCity project will ultimately result in better solutions, more awareness and increased flood management capacity in the cities of Bradford, Brussels, Dublin, Leuven, Mainz, Nijmegen, Orleans and Paris. The project will activate a structural change in the mindset of the politicians, professionals and public in these partner cities. This change concerns a recognition of the importance to address all 4-'A's (Awareness, Avoidance, Alleviation and Assistance) in sustainable flood risk management policies (Figure 1). 


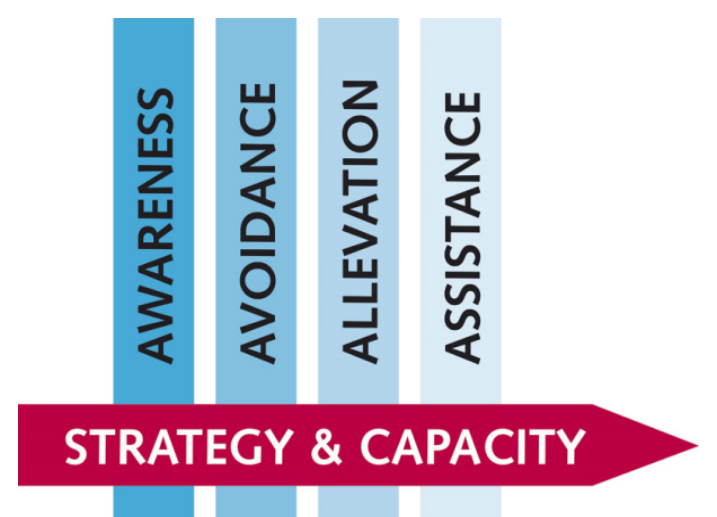

Figure 1. 4-A approach used by the FRC project

The European Framework Programme 6 project FLOODsite was completed in 2009 (www.floodsite.net). This major consortium covered the physical, environmental, ecological and socio-economic aspects of floods from rivers, estuaries and the sea. It considered flood risk as a combination of hazard sources, pathways and the consequences of flooding on the "receptors" - people, property and the environment (Samuels et al., 2009).

COST Action C22 (2005-2009) brought together a large number of European research groups with the objective to improve the knowledge that is required for preventing and mitigating potential flood impacts in urban areas (Ashley et al., 2007). Their work was organised around four areas: (i) flood modelling and probability assessment, (ii) flood risk assessment and mapping, (iii) flood resilience, and (iv) integrative concepts in urban flood management.

Examples of other flooding and water related research projects and initiatives in the context of the EU water policy and related scientific framework are given by Quevauviller et al. (2010).

As in many European countries, the French National Agency for Research - ANR - has initiated a research agenda entitled Sustainable Cities. This framework has the ambition to promote multidisciplinary approaches addressing the various issues of urban development. A specific action called Resilis has been initiated in 2009 and will address the various aspects of the resilience concept at the city scale especially regarding natural hazards.

Another big national action is the UK Flood Research Management Research Consortium (www.floodrisk.org.uk/). Over the past eight years, this project addressed key issues in flood science and engineering and the portfolio of research includes the short-term delivery of tools and techniques to support more accurate flood forecasting and warning, improvements to flood management infrastructure, and reduction of flood risk to people, property and the environment (Pender and Faulkner, 2011). A particular feature of the 2 nd phase of FRMRC is the concerted effort to focus on coastal and urban flooding.

The Danish Water and Wastewater Association (DANVA) has taken the strategic decision to carry out research directly applicable to the Danish utilities and municipalities on adaptation to climate change. So far the outcome of the DANVA research programme is the description of new extreme "climate proof" design rainfall (DANVA, 2007a), and a set of guidelines for the Danish municipalities concerning how to analyse the impact of climate changes in a consistent framework (DANVA, 2007b). These research projects provide the Danish municipalities with the consistent methodologies to develop a timely and cost efficient strategy for coping with climate changes and their impacts on sewer systems. The guideline contains: (1) three levels of analysis depending on the complexity of the sewer system, and (2) a framework for its analysis, and where and when the impact from increased rainfall due to climate change statistically will violate today's standards - will it be in $10,25,50$, or 100 years or is today's design climate proof?

In Denmark, sewer systems are typically analysed by Chicago Design Storms (CDS) or historical rain series. To investigate the effect of climate change, the rainfall totals used today are multiplied by 1.4 , corresponding to the expected growth in rain intensity. The factor of 1.4 is the outcome of a comprehensive climate change study for Denmark (Spildevandskomiteen, 2008). By using this rainfall in modelling studies, critical locations or areas in the catchment can be identified, and it can be decided how and when problems have to be solved. It is proposed that clarification of the impacts of climate change is carried out on three levels: 
Level 1. Check if the impacts of climate changes will result in a violation of the Standards.

Level 2. If the Standard is violated, then an estimate of the extent of the violation is required, i.e. estimate the flood depth, extent, and damage.

Level 3. If the flood extent, depth, and damage are significant and are due to changes in the climate, this assessment must feed into a prioritized planning scheme on how to mitigate the expected problems.

When a complete problem identification has been carried out, the problems should be prioritised e.g. by use of a risk assessment.

The assessment of the impact of climate change on sewer systems will be a continuous process in the future. Information about the development of the climate and downscaling of extreme rainfall events to the city level will continue to be improved and refined (Sunyer et al., in press). During the CORFU project, different methods for estimating extreme rainfall and its impacts will be assessed. As such, CORFU will not develop new methods for downscaling extreme rainfall. Hence, it is expected that the evaluation of climate change impacts on sewers will be an ongoing process, where new and improved information concerning climate scenarios and their associated uncertainty will be updated and made available to the municipalities on a regular basis. It is expected that new information concerning changes in the climate will involve minor adjustments of existing scenarios, e.g. in the form of a better geographical resolution of the variation of precipitation over local areas.

The increase in a Danish 10-year rainfall event for Scenario A2 will be $40 \%$ by 2100 , i.e. the rainfall intensity in the time series for the design storm is increased for each time step by $40 \%$. Scenario A2 is the worst of the three scenarios adopted by the Danish EPA and futures scenarios different to those predicted in A2 may occur. If all Danish sewers were to be upgraded today to comply with the rainfall foreseen in scenario A2, then the additional yearly investment in Danish sewers would be in the order of magnitude of $20 \%$ (a first estimate) of the yearly maintenance budgets. As the future is uncertain, the main idea behind the recommendation to the municipalities is: not to sit and wait until climate changes are $100 \%$ documented based on historical records; not to invest heavily today in upgrading the entire infrastructure as soon as possible; to comply with the worst case future climate scenarios; to get an overview of the possible consequences of the likely impact of climate change, and then to incorporate that knowledge into their maintenance plans. Based on these ideas, the municipalities are strongly recommended to develop a plan for timely management with constant care to handle the impacts arising from climate change. The plan must contain the following:

- $\quad$ Planning and design of new sewer systems under the influence of climate changes.

- Guidelines for sewers, for which maintenance and reconstruction projects are already planned, taking into consideration the impact of climate change.

- Guidelines for the analysis of climate change impacts on sewer systems, for which no maintenance or reconstruction plans are scheduled.

\section{Elements of resilient flood management strategies}

\subsection{Urban planning policies}

Even at the early stages of the CORFU project, it has become clear that the severity and frequency of urban flooding can be reduced by better planning policies, which specifically address flooding issues at an early stage. This implies careful consideration of the drainage 'major system' (i.e., the above ground flow pathways as opposed to the piped system) at the planning stage and its incorporation (and protection) into the urban landscape. Butler and Davies (2011) argue that a range of possible flood mitigation measures are possible involving the major system, as follows:

- Reduce or limit inflow to the minor system; the most important approach is the use of source control or SUDS (sustainable drainage systems) measures to infiltrate flow locally, or to store and reuse it. An alternative approach is to divert or disconnect flows to alternative systems or outfalls via overland flow paths.

- Store more flow in the major system to attenuate flow, and therefore reduce peak flow-rates. Storage can be provided at source (SUDS) or in surface features.

- Better design and deployment of surface flow features.

- Improve flood resilience of buildings. 
- Improve communications and accountability across stakeholders.

The surface conveyance system for flood flows is made up of many elements, including gully inlets/catchbasins, pathways, roads, drives and other less formal flow pathways. Gully inlets are a key interface between the major and minor system, and attention needs to be focused on selecting the appropriate capacities and spacing of inlets. When planning new sites, the most effective approach is to follow natural pathways as far as possible, providing linked, free passage for flowing excess water. This includes identification of points of entry and exit to the drainage system, as well as the location of effective flow barriers such as kerbs, walls, buildings and other relevant urban features. Legal safeguards and appropriate maintenance will be needed to ensure their continued availability. At the larger scale, river floodplains or green corridors can serve a similar purpose.

Surface storage capacity can be developed to replace or reduce the need for extensive surface pathways. The key points about major system storage areas are that they are aboveground, multifunctional facilities that are used infrequently. Their goal is to retain the flood volume temporarily and release it slowly at a lower flow-rate. A wide range of alternatives is available (Butler and Davies, 2011). A good example is a car park, where water can be allowed to accumulate up to kerb height over a defined area. Although vehicle owners may be temporarily inconvenienced, there is unlikely to be any significant structural damage to the site after flooding, safety risks are minimal due to the low depths, and as long as the area can be adequately drained after the event, normal use can be quickly resumed.

In many cases, the effects of flooding can be minimised and resilience improved by the careful positioning of buildings in relation to the topography and the defined flood pathways, and by the sympathetic design of landscaping features. It is important to also ensure floor levels are correctly set relative to the major system. Valuable flood protection can be achieved by careful detailing of the property and surrounds including entrance details, driveway slopes and drop kerbs. Two examples are shown in Figures 2 and 3.
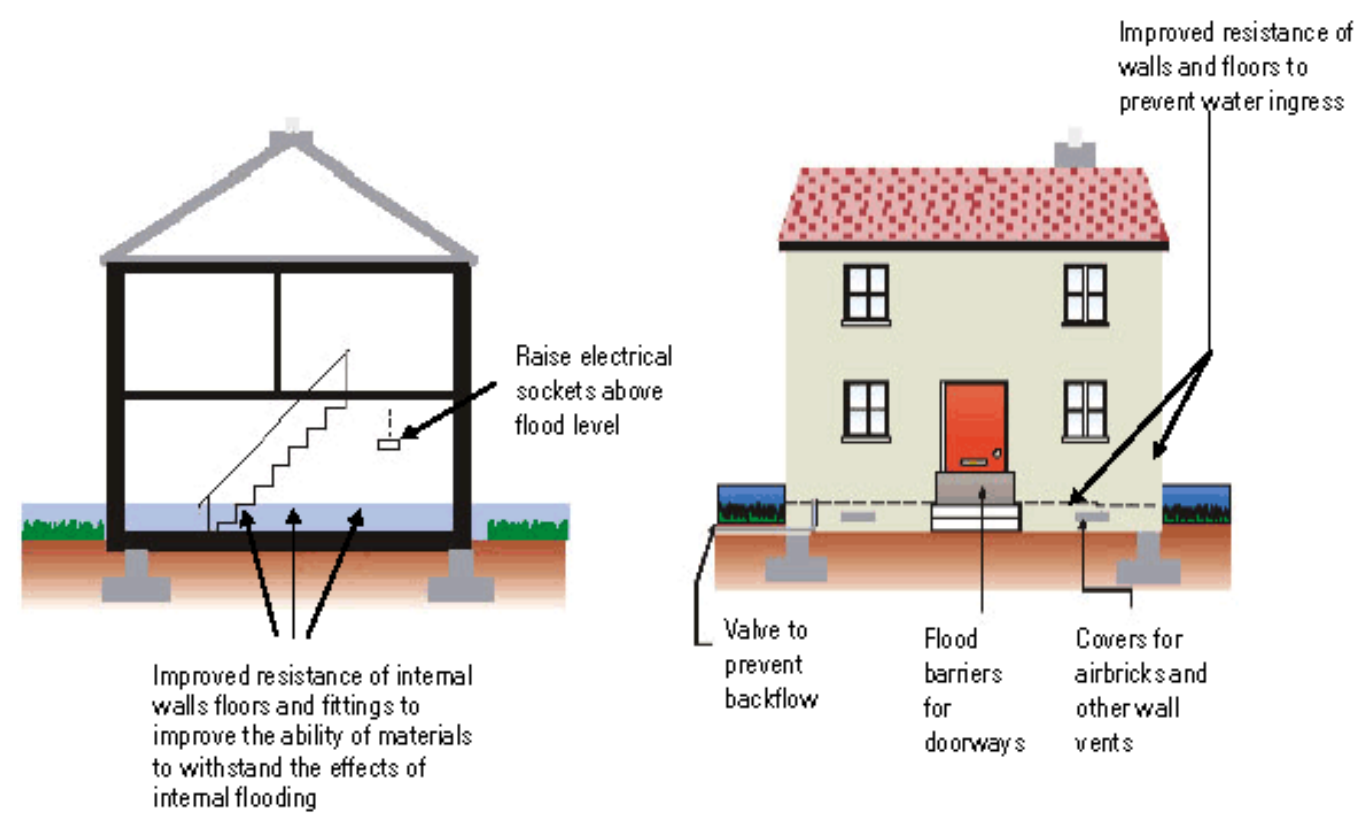

Figure 2. Example of adaptation to flood (Scottish Government, 2004)

The final, and perhaps most important aspect, both at the planning stage and subsequently, is to ensure accountability, communication and hence resilience amongst urban stakeholders. To try and implement this, the concept of integrated urban drainage (IUD) has been developed that takes account of key aspects of urban drainage, and produces long term, holistic and sustainable plans for its management and development (Defra, 2005; Balmforth et al., 2006). 


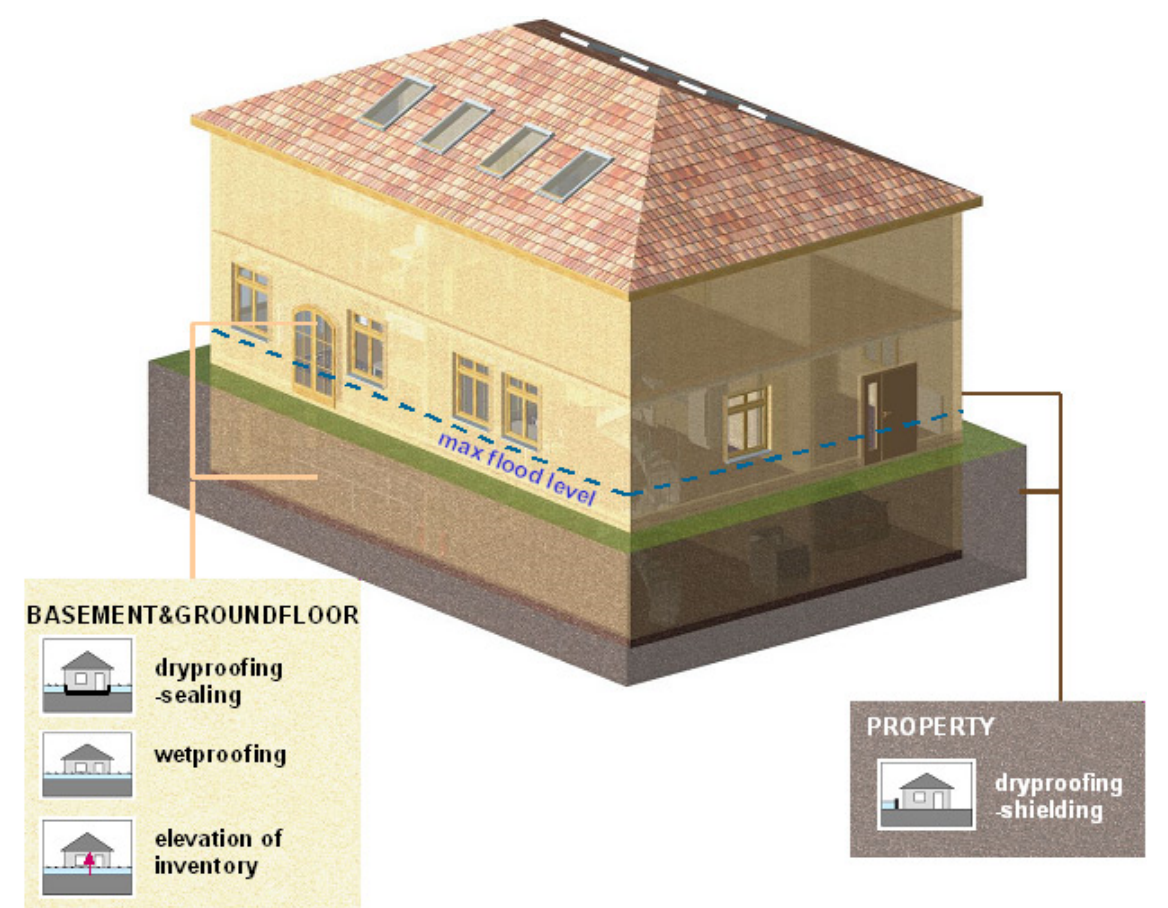

Figure 3. Example of resilient building promoted in Hamburg

\subsection{Real-time urban flood information systems}

Urban flooding is inevitable as all urban drainage systems are designed for a given return period. Hence, it is a must to have emergency plans at hand when the rainfall exceeds the design criteria. A real time urban flood information system makes it possible to increase the warning time and to get an earlier start on the implementation of the emergency plans, and subsequently it reduces the urban flood damages. The warning time depends on the concentration time of the catchment and can typically be extended with 1/2-1 hour by the use of a real time rain forecast by radar (Hénonin et al, 2010). In CORFU the concentration time for the test-cases ranges from about 20 minutes in Nice, to 3-4 hours in Dhaka city, so it will be a challenge and a research objective to investigate if real time modelling can provide sufficient warning time for the cities. During the CORFU project, various real time flood forecasting methodologies will be developed, compared, and evaluated. For example, traditional deterministic forecast models will be compared with a probabilistic flood forecast model focusing on the rainfall uncertainty and the consequent impact on the forecasted flood maps (Renee, 2011). Finally, real time data assimilation will be built into the forecast system in order to evaluate the increase in precision and to test if such an updating of the model is feasible in real time.

Before embarking on providing real-time hydrological information, it is important to assess which information individual members of the public would like to have, and which information local authorities would like to have in order to manage the assets of the city. Whereas the public require information which is simple, clear and concise to help them understanding the risk, the local authority requires more comprehensive information to implement and co-ordinate the flood response strategy (Parkinson and Mark, 2005). Hence, before starting to disseminate real time hydrological information it is important to address the following questions:

(1) What is valuable real-time hydrological information for the public?

(2) How and where should the real-time information be presented to the public?

(3) When does hydrological data change from being valuable real time information to becoming less interesting (from a public point of view) historical hydrological data?

(4) What does it take in terms of knowledge, technology and hardware to provide real-time hydrological information?

Figure 4 illustrates a typical structure for a real-time control system for monitoring and responding to the flood risk. 


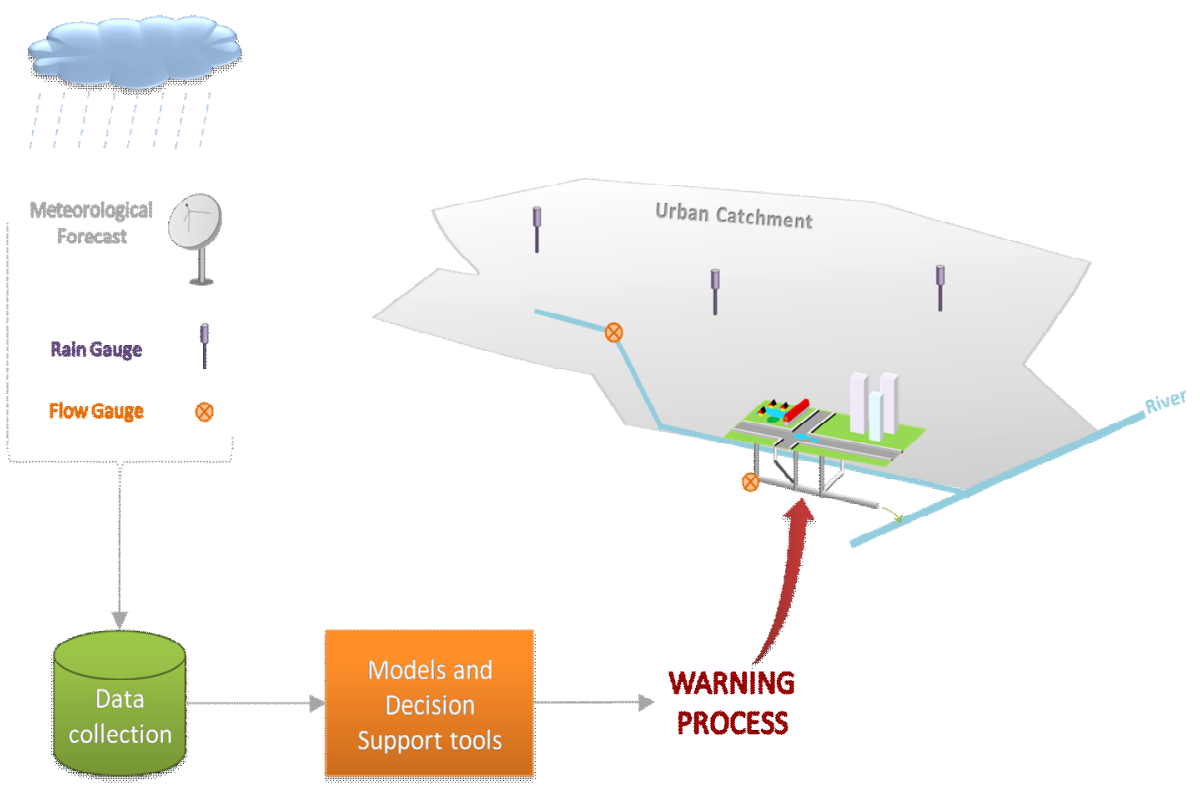

Figure 4. Typical layout of a real time urban flood information system.

Communication is critical during a flood incident in order to ensure that mobilisation of communities and evacuation response strategies are to be effective. The local authority may want to process the rainfall information further and pass it to public information sources like traffic radio, local news broadcasts, etc.

\subsection{Resilience measures}

A holistic approach is needed in order to achieve a comprehensive and global vision that is able to fit with the expectations of each urban society under the constraints of climate change. The experiences of many cities around the world affirm that a "no-regrets" approach to mitigation and adaptation initiatives can be highly effective and sustainable. This approach promotes the necessary changes in behaviour, technology, and policies as simply sound urban management necessary under any circumstances. When this "no-regrets" approach is supplemented with specific measures on climate change impact mitigation and adaptation and on disaster risk management, the probability of enhancing a city's resilience capacity becomes very high. Urban growth should become synonymous with "walkable cities" and energy conservation. Urban development models centred on the automobile, suburban living, and cheap fuel will need to be based on other more efficient conditions. Having compact, efficient, and walkable cities is an important mitigation measure. Equally important is safety in building siting, design, and codes as a key adaptation measure, especially for the poor, to avoid settlements on marginal lands most susceptible to climate change impacts and other natural hazards.

In a very operational way, strategies at the local scale have been promoted in Europe with the ambition to democratise the resilience concept for each building. In that context, resilience assumes sustainable measures that can be incorporated into the building fabric, fixtures and fittings to reduce the impact of floodwater on the property. This allows easier drying and cleaning, ensures that the structural integrity of the building is not compromised and reduces the amount of time until the building can be reoccupied. The UK Department for Environment, Food and Rural Affairs (Defra) has overall policy responsibility for flood and coastal erosion risk management in England. The strategy promotes sustainable and appropriate development and, where necessary, recommends constructing buildings, with appropriate flood resistant and resilient measures in areas that have a residual risk of flooding (CIRIA, 2007). It is not possible to defend and protect everywhere, and people and property will still be at risk from severe, exceptional floods that are beyond the design standards of flood defenses. It is clear, however, that the use of resilience should not be a means for by-passing the necessary planning requirements. Such a type of strategy represents a fundamental step which has to be amplified in order to address the global dimension of cities, both in Europe and Asia, with the willingness to promote new paradigms for resilience concept implementation (Veerbeek and Zevenbergen, 2008). 


\section{The CORFU approach}

The differences in urban flooding problems in Asia and in Europe range from levels of economic development, infrastructure age, social systems and decision making processes, to prevailing drainage methods, seasonality of rainfall patterns and climate change trends. The vision of the CORFU project is to use these differences to create synergies that will bring new quality to flood management strategies globally, through cross-fertilisation of the latest technological advances with traditional and emerging approaches to living with floods.

The research is building up on both the CORFU team experience and tools as well as on general scientific and technological progress in the field. In that respect, the results of some of the projects mentioned in Section 3 are directly relevant, such as flood impact assessment methods (FLOODsite), real-time modelling approaches (FRMRC), flood management strategies (AMICE) and flood resilience concepts (COST C22).

The first strand of CORFU research looks at drivers that impact on urban flooding, with the objective to determine the interactions between economic and urban growth, societal trends and the urban structure, which will serve as the basis for the development of a DPSIR (drivers-pressures-state-impact-response) logical framework. The analysis will be completed in conjunction with IPCC-based projections of climate change, economic, health and social development, aiming at identifying the future policy areas where the responses to the drivers and pressures can be most effective. This will be achieved through developing a fundamental understanding of how human capacity and action can shape the future dealing with urban flooding by identifying the future mechanisms, through which feedback to drivers/pressures can be achieved and delivered to stakeholders.

The main novelty of this part of research is the way in which urban growth and economic growth models are implemented in the context of resilience to urban flooding. This will involve modelling of the effects of different elements of urbanisation (e.g. green corridors) on flood risk as well as the effects of flooding on economic activity.

The methodologies and tools for off-line and real-time flood hazard assessment based on urban flood modelling will be enhanced. Missing elements in existing models for system analysis will be developed in order to identify consistent procedures for the calibration of urban flood models at different scales, having in mind the envisaged technological advances - wider availability of weather radars and on-line rain gauges, increase in computer speed and possibilities for coupling of runoff-sewer-river hydrologic and hydraulic models. Most of the CORFU case study areas already have hydraulic models of drainage systems and potentially flooded urban catchments. These range from 1D river models to coupled 1D/2D models of sewer networks and urban surfaces.

Relevant methodologies for urban flood analyses associated with the choice of urban flood model will be revisited, based on the analyses of required resolution and level of detail in data about terrain, landuse, sewer network and structures, adequate for different scales. The ultimate objective is to develop generic tools for urban flood mitigation plans and test real-time urban flood forecast systems, including real-time data assimilation and uncertainty estimates. This will enable evaluation of future impacts of urban growth and climate change on flood probability through scenario studies.

The next objective is to develop a comprehensive and flexible framework that will amalgamate different methodologies for evaluation of tangible (direct and indirect) and intangible damages. Assessment of health problems will be taken to a higher level by a combination of hydraulic modelling of floods and quantitative microbial risk assessment, through simulation of the transport of pollutants following surcharging from combined sewer systems. Consequent exposure times and health effects will be quantified through DALYs (Disability-Adjusted Life Years).

Interrelationships between risk perception, level of preparedness and actual responses will also be studied, distinguishing between impacts on individuals and on communities. All this will enable comprehensive and realistic assessments of the vulnerability to urban flooding at different spatial and temporal scales, aiming at the quantification of the efficiency of adaptive management strategies related to changes in drivers in alternative scenarios context and of the cost-effectiveness of resilient measures.

The existing flood risk management strategies will be assessed. These will encompass planning and prevention for the minimisation of flood risk, management during flood events including early warning systems, emergency protocols and crisis management and measures to be taken after a flood event, 
evaluation of damages, recovery measures and the procedures that allow learning from experience. This approach ensures comprehensive coverage of the whole flood management cycle. A general strategic scheme for urban planning will be developed and tested, such that flood resilience is defined and implemented according to the situation of any city. The ultimate objective will be to formulate good practices and good standards that can be implemented nationally in partner countries.

CORFU research involves eight case studies in Europe and Asia - Barcelona, Beijing, Dhaka, Hamburg, Mumbai, Nice, Seoul and Taipei. The new strategies will be investigated and enhanced through these case studies. Comparisons will be made by the analysis of possible effects of the implementation of new approaches in cities in different socio-economic systems, different climate zones and with varying quality of data available. Workshops in each case study area have been organised in the first period of the project $(2010-2011)$ to scope the work, and dissemination workshops will be held towards the end of the project (2013-2014).

A particular issue in this research is the question of spatial and temporal scales at which different models are to be applied and how the results obtained on a certain scale are used on a smaller scale and vice versa. For example, all case study areas are limited either on a city or on a part of the city, whilst economic activity models will usually be related to wider regions. Regarding real-time rainfall inputs, their resolution will be defined based on the density of available rain-gauge network or weather radar resolution; rainfall inputs for off-line analysis based on climate change predictions will require downscaling, typically to $2 \mathrm{~km}$ or $1 \mathrm{~km}$ grid resolution, adequate for the urban area. The latter introduces additional uncertainty in the results, although experience in this domain exists (e.g. Burton et al., 2010).

\section{Concluding remarks}

Increased frequency and intensity of flooding events, combined with trends in growing urban population in most countries have led to the need for increased and internationally coordinated efforts to enhance technologies and policies for dealing with floods. A number of national and international research programmes have made good progress in this respect, but much more is needed in order to improve flood management strategies. The CORFU project has adopted an original approach that aims to quantify the cost-effectiveness of resilience measures and integrative and adaptable flood management plans for different scenarios. Flood impacts in urban areas - potential deaths, damage to infrastructure and health problems in the first place and consequent effects on individuals and on communities - and possible responses will be assessed by envisaging different scenarios of relevant drivers: urban development, socio-economic trends and climate changes.

In order to conduct the calculations and analysis described above, a number of models are being developed (or enhanced) for case study areas, including urban growth models, social and economic activity, hydrological/hydraulic flooding models, damage assessment models, as well as the models that quantify the effectiveness of resilience measures. It is believed that the way in which the different models are being put together, combined with the variability of conditions in the case study areas in Asia and in Europe, will ultimately enable more scientifically sound policies for management of the consequences of urban flooding.

\section{Acknowledgments}

CORFU project is funded by the European Commission through Framework Programme 7, grant number 244047.

\section{References}

Ashley, R., Garvin, S., Pasche, E., Vassilopoulos and Zevenbergen, C. (Eds.) (2007) Advances in Urban Flood Management, Taylor \& Francis, London.

Balmforth, D., Digman, C., Butler. D. and Shaffer. (2006) Integrated Urban Drainage Pilots Scoping Study Report. Defra/CLG.

Burton, A., Glenis, V., Bovolo, C.I., Blenkinsop, S., Fowler, H.J., Chen, A.S., Djordjevic, S. Kilsby, C.G. (2010). Stochastic rainfall modelling for the assessment of urban flood hazard in a changing climate, BHS Third International Symposium, Managing Consequences of a Changing Global Environment, Newcastle, 19-23 July.

Butler, D. and Davies, J.W. (2011) Urban Drainage, 3rd Edition, Spon Press, London. 
CIRIA (2007). Improving the Flood Performance of New Buildings. Flood resilient construction. RIBA Publishing, London.

DANVA (2007a) Klimaændringernes betydning for ændringer i kraftig nedbør i høj opløsning i tid og sted. (in Danish)

DANVA (2007b) En kogebog for analyser af klimaændringers effekter på afløbssystemer - med fokus på oversvømmelser. F\& U rapport nr. 5. ISBN: 87-90455-74-6 (in Danish)

Defra (2005) Making Space for Water. Taking Forward a New Government Strategy for Flood and Coatal Erosion Risk Management in England. Department for Environment, Food and Rural Affairs.

European Commission (2010). World and European Sustainable Cities, Ref: EUR 24353, Brussels.

Gersonius, B. (2008) Can resilience support integrated approaches to urban drainage management? 11th International Conference on Urban Drainage. Edinburgh, Scotland.

Hénonin, J., Russo, B., Roqueta, D.S., Sanchez-Diezma, R., Domingo, N.D.S., Thomsen, F. and Mark, O. (2010). Urban flood real-time forecasting and modelling: A state-of-the-art review, International MIKE by DHI Conference, 6-8 September, Copenhagen.

Hulme, M., Jenkins, G.J., Lu, X., Turnpenny, J.R., Mitchell, T.D., Jones, R.G., Lowe, J., Murphy, J.M., Hassell, D., Boorman, P., McDonald, R. And Hill, S. (2002). "Climate Change Scenarios for the United Kingdom: The UKCIP02 Scientific Report", Tyndall Centre for Climate Change Research, University of East Anglia, Norwich.

IBRDNB (2009) Climate Resilient Cities, International Bank for Reconstruction and Development/The World Bank Washington.

IPCC (2007). "Climate Change 2007: Synthesis Report. Contribution of Working Groups I, II and III to the Fourth Assessment Report". http://www.ipcc.ch/pdf/assessment-report/ar4/syr/ar4_syr.pdf.

Murphy, J., Sexton, D., Jenkins, G., Boorman, P., Booth, B., Brown, K., Clark, R., Collins, M., Harris, G. And Kendon E. (2009). "Climate Change Projections, Version 2, UK Climate Projections", http://ukclimateprojections.defra.gov.uk/content/view/824/517

Parkinson, J. and Mark, O. (2005). Urban Stormwater Management in Developing Countries, IWA Publishing, London.

Pender, G. and Faulkner, H. (Eds.) (2011). Flood Science and Management, Wiley-Blackwell.

Quevauviller, Ph., Christos, F. and Balabanis, P. (2010) "General Features of the EU Water Policy and Related Scientific Framework", Chapter 1.4 in: Water System Science and Policy Interfacing, RSC Publishing, 52-62.

Renee, J.-R,. (2011) Probabilistic Real-Time Flood Forecasting in the Urban Context, MSc Thesis (WSE-HERBD11.10). UNESCO-IHE Institute for Water Education, Delft.

Samuels, P., Huntington, S., Allsop, W. and Harrop, J. (Eds.) (2009). Flood Risk Management: Research and Practice, CRC Press/Balkema.

Scottish Government (2004). Planning and Building Standards Advice on Flooding (Note PAN 69). (http://www.scotland.gov.uk/Publications/2004/08/19805/41597)

Song, L., and Woo, W. T. (2008). "China's Dilemma - Economic Growth, the Environment, and Climate Change" Asia Pacific Press, Canberra.

Spildevandskomiteen (The Water Pollution Committee of the Society of Danish Engineers). (2008), Skrift 29 Forventede ændringer i ekstremregn som følge af klimaændringer. (in Danish)

Sunyer, M.A., Madsen, H. and Ang, P.H., (in press). A comparison of different regional climate models and statistical downscaling methods for extreme rainfall estimation under climate change, Atmospheric Research, Accepted.

Veerbeek, W., Zevenbergen, C., and S., H. v. (2008). "Urban Flood Management: Towards a Flood Resilient Urban Environment." SIBICO International (eds) Conference Proceedings Water resources systems management under extreme conditions, Moscow, 465-471.

\section{Authors}

Slobodan Djordjević

Slobodan Djordjević is Associate Professor of Hydraulic Engineering and Director of Education (Engineering studies) at the University of Exeter, United Kingdom. Previously he was Assistant Professor at the University of Belgrade, Serbia where he obtained degrees in civil engineering. His research interests include the development and application of advanced tools for simulation, design and management of water systems, all aspects of urban flooding, mixed (transcritical and freesurface/pressurized) flow regimes, the performance of sewer networks, combined risks from different extreme weather events under climate change, CFD, GIS, karst hydrology and the modelling of water quality in rivers and large water bodies. Professor Djordjević is an Associate Editor of IWA Water Science \& Technology journal and the CORFU Project Coordinator. 
David Butler

David Butler is Professor of Water Engineering and the Associate Dean for Research at CEMPS, University of Exeter and formerly professor and head of the Urban Water Research Group (UWRG) at Imperial College London. He is a chartered civil engineer and a chartered environmentalist, and a Fellow of both ICE and CIWEM. Professor Butler specialises in sustainable urban water management, water conservation and recycling, integrated modelling of urban water systems, spatial water management, operational management of stormwater runoff and flooding, in-sewer processes and decision support tool development. He was Director of the WaND consortium, Director of the WATERSAVE network, a member of CIRIA's Water Engineering Advisory Panel and FWR's Wastewater Research and Industry Support Forum and is editor-in-chief of the Water \& Environment Journal (CIWEM) and the Urban Water Journal.

\section{Philippe Gourbesville}

Philippe Gourbesville is the Director of Polytech Nice Sophia, the engineering school of Nice Sophia University (UNS), France. He is the Professor of Hydroinformatics and Water Engineering at UNS and is a visiting professor at Newcastle University, Brandenburg University in Cottbus, Technical University of Catalunya, Ecole Polytechnique Fédérale de Lausanne, Asian Institute of Technology, Singapore National University, Beijing University of Technology, Seoul National University, and Kyoto University. Before joining NSU, he spent ten years as hydraulic engineer for a consulting company involved in many international projects. Since 2004, under the Erasmus Mundus, he developed the first joint master degree, EuroAquae, focused on hydroinformatics. Professor Gourbesville's research and teaching interests are focused on urban water management, urban flooding processes, distributed physically based modelling, impact assessment, integrated water resources management, ICT \& architecture of modelling systems, collaborative engineering and virtual environments.

\section{Ole Mark}

Ole Mark is Head of Research and Development at Danish Hydraulic Institute (DHI). He is a specialist in climate change and urban water systems, with a focus on sewer, drainage and surface water in the cities. His work is highly focused on research and practical problem solving within the hydrological cycle, including urban flooding and urban water impacts on the receiving waters. Dr Mark spent three years as Associate Professor and Programme Coordinator at the Asian Institute of Technology in Thailand and he has been a visiting lecturer/professor at a number of institutions worldwide. His work experience comes from both the developed and the developing countries. Dr Mark is one of the authors of the book "Urban Stormwater Management in Developing Countries" published by IWA and an Associate Editor of the Journal of Hydroinformatics.

\section{Erik Pasche}

Erik Pasche (1955-2010) was Professor at the Technical University of Hamburg and Harburg (TUHH). He conducted research as a NATO fellow at the University of California at Davis. Prior to joining TUHH, he worked ten years as a consultant for Björnsen Consulting Engineers in Koblenz. Professor Pasche specialized in numerical and experimental modelling of hydrodynamic and morphodynamic processes in rivers and coastal zones. He was particularly well known for his work on innovative flood defence techniques, advanced methodologies for evaluation of flood impacts and the development of internet based flood management and decision support systems. Professor Pasche was Vice-Chairman and German representative of the COST initiative C22 Urban Flood Management. He was a visiting professor at the UNESCO-IHE at Delft University and a UK Royal Academy of Engineering Distinguished Visiting Fellow at the University of Exeter in 2008. He was a guiding force in defining the CORFU project. 